\title{
MujERES TRAS LAS CÁMARAS EN EL DOCUMENTAL \\ LATINOAMERICANO. CONCLUSIONES DE UN ESTUDIO \\ TRANSVERSAL DE LA EVOLUCIÓN HISTÓRICA
}

\section{Women behind the camera in Latin American \\ documentaries. Conclusions from a transverse study of their bistorical evolution}

\author{
Dr. Pablo CALVO DE CASTRO \\ Profesor de Tiempo Completo \\ Universidad de Medellín, Colombia \\ E-mail: pcalvo@udem.edu.co \\ (iD http://orcid.org/0000-0002-7537-2349
}

Fecha de recepción del artículo: 30/03/2019

Fecha de aceptación definitiva: 20/04/2019

\begin{abstract}
RESUMEN
El presente artículo analiza las aportaciones de las directoras de cine documental en el contexto de producción latinoamericano. La premisa de partida las sitúa en una posición de desigualdad en relación con la contribución de los hombres y su preeminencia en un sector inserto en un contexto social dominado por el machismo estructural. Se emplea una metodología cualitativa a través del análisis fílmico a partir de una muestra de 100 títulos relevantes del documental latinoamericano. Los títulos analizados dibujan un recorrido que se inicia con las contribuciones germinales en el Nuevo Cine Latinoamericano y que culmina en el momento actual. En los últimos años el documental en América Latina está viviendo un proceso de consolidación una vez ha alcanzado su madurez en el contexto de creación con mayores posibilidades de las que ha conocido la historia del cine.
\end{abstract}

Palabras clave: cine documental; mujer; América Latina; nuevo cine latinoamericano; evolución histórica.

\begin{abstract}
This article discusses the contributions of the woman film directors in the context of the Latin-American production. The starting point is based on an inequality position regarding the achievements of men and their preeminence in a sector which belongs to a social frame characterized by a structural machismo. A qualitative methodology is used through the film analysis of a sample composed by 100 relevant works of the Latin-American documentary genre. The films draw a path that begins with the seminal contributions in the New Latin-American Cinema and concludes nowadays. Over the last few years documentary in Lat-in America has been undergoing a consolidation process once that it has reached its maturity in the land-scape of creation, with more possibilities than it has ever had in Film History.
\end{abstract}


Key words: documentary cinema; woman; Latin American; new latin american cinema; historical evolution.

\section{INTRODUCCIÓN}

Cuando Carmen Toscano realizó Memorias de un mexicano (1950) seguramente no fue consciente de la trascendencia de su aportación a la cinematografía documental latinoamericana. La película está construida a partir del extenso material de archivo que su padre, Salvador Toscano, y su equipo de colaboradores elaboraron registrando los convulsos momentos que vivió México a principios del s. XX. Memorias de un mexicano (1950) puede ser analizada como película histórica mediante la puesta en valor de un material fílmico de gran relevancia, como ejercicio de apropiación y de montaje o como un documental intensamente vinculado a las estrategias narrativas de la ficción, pero sobre todo es la aportación de una cineasta en un contexto profesional dominado por los hombres y en unas circunstancias sociales afectadas por un machismo que es estructural en la región (Felitti y Rizzotti, 2016, p. 25).

Si bien ha habido pioneras que han realizado grandes aportes a las filmografías latinoamericanas delante y detrás de las cámaras, Carmen Toscano es un hito en la región e inmediatamente después aparecen otras, como Margot Benacerraf, que van a tener gran influencia en la llegada de las distintas ramificaciones e interpretaciones del Nuevo Cine Latinoamericano en las décadas de los sesenta y setenta. Estas influencias, complementarias, se producen en un cine documental desarrollado en un plano de total independencia (Iglesias y Fregoso, 1998) -favoreciendo un contexto de experimentación (Ortega, 2009) - que ha tenido condiciones similares para creadores de ambos sexos. Esta independencia ha permitido la libertad creativa, pero también ha supuesto la escasez de recursos (King, 1994, p. 107) para producir historias que tienen un impacto muy minoritario en el público generalista y una complicada amortización (Mamblona, 2012, p. 186). Esta situación genera que, tradicionalmente, los programas de ayudas internacionales a la creación, las becas y la financiación que ofrecen algunos festivales y organizaciones supranacionales hayan sido fuentes imprescindibles para la obtención de recursos. Como apuntan Austin y De Jong (2008, p. 1) «los primeros años del siglo XXI han sido testimonio de los significativos y continuos cambios en las dimensiones tecnológica, comercial, estética, política y social del documental producido para, y visto por, una amplia gama de múltiples escenarios». Partiendo de este contexto de escasez financiera estructural, quizá la clave está en la irrupción de avances técnicos como el vídeo en la década de los 80 y de los medios digitales a comienzos del s. XXI, junto a cuestiones sociales más transversales como el aumento del acceso a las oportunidades de formación especializada en escuelas y universidades en la región (Calvo de Castro, 2018a, p. 168) así como el crecimiento de la clase media, han supuesto un incremento exponencial de las posibilidades de producción y han permitido visibilizar de manera más justa -aunque todavía incompleta- las aportación de las mujeres en el cine documental en América Latina.

Es necesario mencionar que tanto la selección de la muestra utilizada como las conclusiones generadas de su análisis pertenecen a un estudio de mayor espectro que trata de paliar las carencias en lo que respecta a las revisiones de la situación general del cine en la región.

Las conclusiones vertidas en este artículo son el resultado de un recorrido parcial, pero consideramos necesario efectuar este tipo de ejercicios en tanto la presencia de 
las mujeres documentalistas en América Latina aumenta en los últimos años, ya que "para muchas profesionales [es] más fácil acceder al cine documental que al cine de ficción, debido a que es más cara la producción de este último» (Bernárdez-Rodal y Padilla-Castillo, 2018, p. 1250). En este contexto de creación, a partir de finales de los años 90, punto de inflexión definido por Torres San Martín (2014, p. 25) para la verdadera democratización del género en la región, las documentalistas han incrementado su presencial en el contexto de creación. Observar cuáles han sido sus principales influencias desde el punto de vista de las realizaciones hechas por mujeres va a resultar clarificador del contexto actual de creación. Además, utilizar esta estrategia de discriminación positiva parece indispensable para poner en un plano paritario las aportaciones que desde el punto de vista cinematográfico han realizado las mujeres directoras a lo largo de la historia del cine documental en América Latina.

En el análisis de títulos contemporáneos se podrá comprobar cómo las cuestiones que determinan en la actualidad el cine documental a nivel global -la reflexión discursiva, la autorreferencialidad, los posicionamientos frente a la memoria histórica y el matiz experimental que tradicionalmente maneja este formato audiovisual- serán analizadas por las cineastas de manera trascendente en la medida que el cine documental es utilizado, en este contexto, como herramienta para el cambio (Chanan, 2007).

\section{OBjetivos E HIPÓtesis}

Dentro de una revisión transversal del cine documental en América Latina, observando de manera concreta el papel de las mujeres, se plantea el siguiente objetivo, que deriva en la delimitación de una hipótesis de trabajo:

O.1. Considerar el papel del colectivo de mujeres realizadoras estableciendo cuál ha sido su evolución en la historia del cine documental en América Latina, desde los comienzos hasta la época actual, en un contexto especialmente marcado por el machismo general de muchas de las sociedades latinoamericanas y dentro de un colectivo profesional intensamente dominado por la presencia masculina.

H.1. Las mujeres realizadoras de cine documental en América Latina juegan un papel fundamental en la evolución del género en la medida en que en las últimas cuatro décadas parecen haber incrementado exponencialmente su presencia y relevancia dentro de las distintas cinematografías de la región contribuyendo de manera crucial a la consolidación de un género audiovisual maduro y comprometido con la sociedad que documenta.

\section{MARCo TEÓRICO}

Un análisis sobre la presencia de la mujer en el cine documental sea cual sea el enfoque, requiere tener en cuenta una serie de rasgos comunes que afectan directamente a este objeto de estudio. Este hecho se acentúa si atendemos al contexto de la dirección de cine documental en el ámbito latinoamericano. Partiendo de los postulados teóricos de autores como Laura Mulvey (1975) en torno a la configuración del discurso cinematográfico habitualmente asociado al cine argumental, pero que no excluye al documental, la decodificación del mensaje por parte de la audiencia está 
constantemente matizada por el lenguaje patriarcal. En este sentido, Sharon Lin Tay (2009) establece una serie de relaciones de dominación y subordinación que complementan el discurso sobre la posición privilegiada del género, también en la elaboración del discurso. En el terreno de la creación cinematográfica «la mujer, desde los comienzos de la experimentación con la materia fílmica, ha ocupado un lugar céntrico en el mundo de la producción cinematográfica» (Everly, 2016, p. 179).

En el entorno latinoamericano son pioneras cineastas como Josefina Emilia Saleny en Argentina, Carmen Santos en Brasil, Adriana Ehlers, Dolores Ehlers, Mimí Derba, Elena Sánchez Valenzuela y Cándida Beltrán Rendón en México o Alicia Armstrong de Vicuña y Rosario Rodríguez de la Serna en Chile (Torres San Martín, 2013). Todas ellas aportaron cuestiones relevantes en las primeras narrativas cinematográficas y los primeros dramas pasionales que conmovieron al público latinoamericano en el cambio de siglo. Todas postergadas en los equipos de producción al tiempo que «el cine dejó de ser un pasatiempo para los artistas y se convirtió en un negocio de enorme potencial económico» (Everly, 2016, p. 179).

Este trabajo se centra en la figura de la mujer como directora o realizadora de documentales en el contexto latinoamericano, en tanto «el cine, territorio tradicional y fundamentalmente masculino, se ha visto [...] enriquecido por la presencia femenina» (Iglesias y Fregoso, 1998, p. 15) en un plano de fuerte desigualdad de oportunidades y acceso a los recursos (King, 1994, p. 107) como ha sido el de la producción fílmica en América Latina. Si bien es importante tener en cuenta que esta escasez estructural de recursos no distingue por razones de género, también lo es valorar el machismo que permea en todas las capas de la población y que en el ámbito de la creación cinematográfica ha obligado a las mujeres a partir desde una situación de desigualdad. En este sentido, Teresa Mendicutti apunta que «a la hora de hacer una película sí existe una gran diferencia entre el punto de vista de un hombre y el de una mujer, independientemente de que su visión sea femenina o feminista" (Iglesias y Fregoso, 1998, p. 16). Siguiendo la propuesta de la autora y cineasta, las contribuciones de las realizadoras y directoras no asumen el rol de mero complemento de la creación masculina, sino que aportan un punto de vista que contribuye:

A la construcción de la identidad de las diversas cinematografías latinoamericanas. Pero [...] existe una disonancia evidente en cuanto a la trascendencia de esas aportaciones y la visibilidad que se les da tanto desde el punto de vista cinematográfico como desde el de la divulgación en los diversos foros de la investigación sobre historia del cine (Calvo de Castro, 2018a, p. 164).

Si tenemos en cuenta la evolución del cine documental en América Latina a nivel general, hasta la década de los cincuenta no van a aparecer los pioneros que influyen en las décadas posteriores en la generación de los distintos Nuevos Cines Latinoamericanos. Fernando Birri, Nelson Pereira dos Santos, Jorge Ruíz, Tomás Gutiérrez Alea, Julio García Espinosa, pero también cineastas como Margot Benacerraf y Carmen Toscano modelaron, a través de sus aportaciones, el verdadero cambio de paradigma en el documental latinoamericano.

Además, las oportunidades de formación son escasas en la región y muchos cineastas deben buscar, en este periodo, centros especializados y escuelas de cine en Europa y Estados Unidos. Destacan el Museo del Hombre en París y el Centro Sperimentale di Cinematografia en Roma, que «influyó de modo determinante en los proyectos colectivos de los nuevos cines que proliferaron en el subcontinente hacia 
los 60, con precedentes destacados en Tire die (1960) y Los inundados (1962)» (Ruso, 1998, p. 35). En América Latina, durante las décadas de los cincuenta y sesenta tienen gran importancia en la formación de los nuevos cineastas el centro para el Cine Experimental de la Universidad de Chile y el Instituto Cubano del Arte e Industria Cinematográficos (ICAIC), fundado en 1959 por Julio García Espinosa (Mraz, 1990, p. 131). Esta institución canaliza la formación y la creación audiovisual en Cuba desde la llegada de la revolución. La relación entre las mujeres cineastas cubanas y el ICAIC es cuanto menos paradójica, ya que como apunta Diéguez (2012, p. 151) en Cuba, el gobierno revolucionario «enfatiza el acceso de las mujeres al espacio público, como una revolución dentro de la Revolución, mientras que [...] el mundo cinematográfico [...] enmarca a las mujeres en especialidades que tradicionalmente habían ejercido: maquillaje, vestuario actuación y edición».

Como se ha comentado, se producen dos revoluciones tecnológicas que afectan a la creación documental a nivel global. Son la llegada del vídeo en la década de los ochenta y la irrupción de los medios digitales de grabación, edición y distribución en los primeros años del siglo XXI (Lie y Piedras, 2014, p. 72). Estas dos transformaciones junto a «los cambios socioculturales y políticos de finales de la década de 1990 [aumentaron] la participación femenina en el cine y [renovaron] el discurso feminista» (Torres San Martín, 2014, p. 25). Se produce así un entorno propicio para la verdadera democratización en la creación del cine documental en un contexto social condicionado por la desigualdad y la inestabilidad, lo que lo hace todavía más necesario como herramienta para la denuncia social.

\section{Metodología}

La metodología utilizada para el presente estudio que, como se ha mencionado, parte de otro de mayor espectro en el que se plantea una revisión transversal de la evolución del cine documental latinoamericano, se articula desde una perspectiva puramente cualitativa.

Los resultados sobre la trayectoria fílmica de las cineastas surgen de la revisión de películas representativas en la cinematografía documental latinoamericana. Desde este posicionamiento analítico, se considera el documental como «una obra artística autónoma, susceptible de engendrar un texto que fundamente sus significaciones sobre estructuras narrativas y sobre bases visuales y sonoras, produciendo así un efecto particular sobre el espectador» (Aumont y Marie, 1990, p. 18) que, en el caso del cine documental latinoamericano, sobre todo a partir de la llegada de los Nuevos Cines, tiene que ver con la denuncia social.

Además, las particulares motivaciones que llevan a cualquier cineasta a emprender un proyecto documental parten, en la inmensa mayoría de las ocasiones, de una motivación personal, una vinculación o una especial sensibilidad hacia el tema tratado, sobre todo en un contexto de fuerte desigualdad social en el que el cine documental se utiliza como herramienta para el cambio (Chanan, 2007), lo que genera una necesidad mayor, si cabe, de indagar sobre las aportaciones de las documentalistas.

En el diseño de la investigación, se optó por analizar películas consideradas representativas en la historia del cine documental latinoamericano y no a las realizadoras y sus filmografías por dos razones. En primer lugar, el acceso a todos los títulos realizados por cineastas de larga trayectoria es, en muchas ocasiones, complejo. La 
preservación del material fílmico por parte de las cinematecas de los países no obtiene todos los recursos que serían necesarios y si bien algunas cinematografías, como la chilena o la argentina, tienen muchos de sus títulos accesibles en plataformas de Internet, otras como la colombiana o la cubana no cuentan con programas de digitalización masiva y las películas no han sido editadas en DVD u otros formatos similares. En segundo lugar, tomando en cuenta la especial idiosincrasia de creación del cine documental, definir la película como objeto de estudio valoriza las aportaciones de creadores que han utilizado el cine documental de manera coyuntural o de cineastas cuya filmografía ha sido breve o se ha visto interrumpida. Directores como Margot Benacerraf, Eulogio Nishiyama o Alberto Cabrera Infante - por poner solo algunos ejemplos- alcanzaron a realizar un solo título relevante, pero no por ello la trascendencia de P.M. (Jiménez Leal y Cabrera Infante, 1961, Cuba) o de Araya (Benacerraf, 1959, Venezuela) es menor o menos reconocida. En los casos de cineastas que han desarrollado una filmografía más o menos extensa, más allá de la relevancia de unos títulos sobre otros, se observa una evolución del estilo cinematográfico que no se adscribe a la ortodoxia creativa, sino que se va adaptando a las intenciones del realizador en cada caso. Esto provoca que se utilicen estrategias y estilos de registro de la realidad que no permiten sistematizar la aportación de cada realizador en base a estos, por lo que se considera mucho más oportuno tomar como objetivo de estudio la película documental.

En todo caso, atendiendo a las técnicas utilizadas desde un enfoque cualitativo, las empleadas para obtener los resultados que se destilan en el presente texto, han sido el análisis fílmico, el análisis histórico y contextual, el análisis narrativo y la disección de los aspectos formales (Flick, 2002, p. 226-227). Estos modelos analíticos han sido utilizados con profusión en el cine argumental, pero no se identifica su aplicación con el mismo nivel de intensidad en el documental, donde se observan carencias en la producción bibliográfica de estudios transversales o con cierto recorrido a la hora de analizar periodos o contextos amplios a partir de los que observar evoluciones.

Si bien es cierto que el cine producido en América Latina, argumental y documental, es objeto de estudio por parte de numerosos investigadores, también lo es que existen pocos estudios que aborden el tema desde una concepción regional. Esta línea de trabajo está motivada por la existencia de un cine que se considera latinoamericano en tanto está influido por una serie de factores culturales, pero también vinculados con la desigualdad social y su denuncia en un plano de diversidad, a partir de la llegada del Nuevo Cine Latinoamericano en las décadas de los 60 y 70.

Teniendo en cuenta esta premisa de partida, las obras de teóricos del cine documental en América Latina como Paranaguá (1984, 2003a, 2003b, 2009), Burton (1990), Ruffinelli (2001, 2010a, 2010b, 2012), Gumucio Dagron (1982, 2003, 2011, 2014) u Ortega $(2007,2008,2009,2010)$ son referencias a la hora de acotar un inventario de títulos y su relevancia en las cinematografías nacionales. Del mismo modo, la información obtenida con respecto a los datos de producción de cada uno de los países del entorno define un conjunto de cinematografías que transita a distintas velocidades y con distintos niveles de producción (Caballero, 2006, p. 16). En este punto es necesario mencionar que países como Brasil, México y Argentina lideran la producción regional -sin que haya datos que permitan distinguir claramente entre argumental y documental en todos los países-, a distancia de un segundo grupo de países que, si bien mantienen unos niveles de producción estables, no pueden competir en número de títulos y trascendencia con los tres mencionados. En este grupo se sitúan Chile, 
Colombia, Venezuela, Cuba, Uruguay, Perú y Bolivia, según los datos analizados en los distintos anuarios de cine nacional. Además, hay que tener en cuenta títulos y realizadoras que pertenecen a cinematografías con escaso impacto por falta de una estructura que formalice esa aportación. En este sentido, se toman en consideración aportaciones que, por su especial trascendencia, se incorporan a la muestra analizada a partir de la puesta en valor que han hecho los teóricos del documental antes mencionados.

A partir de estos criterios se obtiene un primer conjunto de 172 películas que pasan a ser 112 una vez son aplicados los criterios de disponibilidad y acceso a las mismas. Mediante un último reparto en base a la nacionalidad y la fecha de producción utilizando la proporcionalidad definida en el diseño, se obtuvieron 100 títulos, de los cuales se identifican 25 dirigidos o codirigidos por mujeres.

Respecto a la estructuración de los datos recolectados una vez definida la muestra, se elabora una ficha de análisis específicamente diseñada para el análisis de películas documentales. Para ello se tuvieron en cuenta las aportaciones de Gómez-Tarín y Marzal Felici (2006) y Gómez-Tarín (2006 y 2011) en tanto sistematizan un modelo de análisis narrativo de obras de ficción. Estos autores proponen una clasificación de los elementos que forman parte de la obra fílmica, mediante los que se obtiene una equiparación -con la necesaria adaptación- del modelo aplicado al cine documental. Clasifican esos elementos en el texto y su estructura, el entorno de producción y recepción y los recursos expresivos -elementos objetivables-, los recursos narrativos, la enunciación y el punto de vista -elementos no objetivables-, así como elementos de interpretación y juicio por parte del analista (Gómez-Tarín y Marzal Felici, 2006). Estos elementos a los que acude el investigador están, a su vez, clasificados en torno a tres grandes áreas que Montiel (2002, pp. 34-36) resume en «el análisis de la imagen y el sonido o de la representación fílmica, el análisis del relato o de sus estructuras narrativas y el análisis del proceso comunicativo y del espectador». De manera esquemática, se describe a continuación el modelo de ficha de análisis elaborado para la sistematización en la recolección de los datos. Datos técnicos: realizador, productor, director de fotografía, montaje, distribución, fecha de producción, actores (en caso de ser utilizados), tipo de cámara utilizada, imagen en color / blanco y negro, tipo de formato de exhibición de la película, duración, características técnicas del sonido y sinopsis, delimitación contextual (contexto de producción de la película, contexto argumental, filmografía, biografía y formación del/la realizador/a), elementos formales referidos a la película (ángulo, composición, perspectiva, uso del campo visual, color e iluminación, movimientos de cámara, movimiento interno, estilo de montaje, análisis del sonido y estructura narrativa) y categoría o subgénero a la que se adscribe dentro del cine documental, a partir de las categorizaciones propuestas por Barnouw (1996), Renov (1993 y 2004) y Nichols (1991, 2013).

Una vez desarrollada la ficha de análisis, con la información obtenida de los pretest y los test aplicados para detectar posibles fallas o carencias en las versiones preliminares de la misma, las aportaciones metodológicas fueron complementadas con las estrategias analíticas aplicadas por Bordwell, Staiger y Thompson (1997), Montiel (2002), Martínez-Salanova Sánchez (2003), Gómez Tarín y Marzal Felici (2006), Cerdán Los Arcos (2015) o Gutiérrez San Miguel (2015), las cuales, si bien están todas orientadas al cine argumental, no están tan alejadas de los planteamientos realizados en la ficha utilizada para el presente estudio. 


\section{Resultados}

En relación con lo planteado en la hipótesis de la que parte este estudio, se analizan a continuación las películas dirigidas por las realizadoras presentes en la muestra seleccionada.

\subsection{Una mirada al pasado para entender el contexto actual. Realizadoras relevantes en el documental latinoamericano en la segunda mitad del} s. $X X$

La primera realizadora que aparece en la muestra es la mexicana Carmen Toscano con su documental Memorias de un mexicano (1950). Hija de Salvador Toscano, precursor del cine en el país, tiene una formación artística muy variada. Su pertenencia a una familia adinerada le permitió estudiar en la década de los treinta en la Escuela Normal Superior y en la Facultad de Filosofía y Letras de la Universidad Nacional (Romero Chumacero, 2005, p. 110) y vincularse a la escena cultural de México de las décadas de los treinta y los cuarenta junto a figuras como Frida Kalho, Antonieta Rivas Mercado y Salvador Azuela. Fue poetisa, escritora, documentalista, directora de cine, productora, editora y guionista de cine y teatro. Con la primera de las dos únicas películas que forman parte de su filmografía, Memorias de un mexicano (1950), se propuso reconfigurar, junto a su padre, las decenas de horas de metraje registrados por la cámara de Salvador Toscano (Miquel y Wood, 2016, p. 10), que constituyen uno de los archivos fílmicos de principios de siglo más importantes de América Latina (Quiroga Echevarría, 2007, p. 41). Continuó su trayectoria en el ámbito cultural desde la televisión y sobre todo desde la literatura. Heredera de su legado es la Fundación Salvador Toscano, creada en 1992 para potenciar la obra de Carmen y Salvador y sobre todo continuar la labor de promoción de proyectos culturales para la sociedad en México.

Margot Benacerraf, con tan solo dos películas en su filmografía, firma con Araya (1959) uno de esos títulos de referencia en la transición entre las películas de las décadas de los cuarenta y cincuenta y el Nuevo Cine Latinoamericano, siendo una de las pioneras de la reconceptualización del documental venezolano y latinoamericano en los años sesenta (Ruffinelli, 2012, p. 23). Su película se aleja de los paradigmas propios del reportaje periodístico del documental de la Segunda Guerra Mundial y la posguerra para introducir el elemento poético a través del lirismo visual y de una estructuración narrativa que responde a patrones del cine de ficción con influencia neorrealista (King, 1994, p. 306). Benacerraf, de origen sefardí, nace en Caracas en 1926, en el seno de una familia acomodada. Es guionista, directora y productora cinematográfica y una de las mujeres que más ha trabajado por el desarrollo del cine en su Venezuela natal. Su labor, vinculada al cine y a la cultura, la lleva a dirigir durante tres años la Cinemateca Nacional e impulsar el Primer Festival Internacional del Film Experimental y de Arte del país. En 1991 fundó junto a Gabriel García Márquez la Fundavisual Latina, encargada del fomento de la cinematografía de América Latina en Venezuela (Tirado, 1988, p. 112).

La colombiana Gabriela Samper se atrevió a hacer cine en su país cuando ninguna mujer lo hacía y abre el camino para otras que vinieron después, como Marta Rodríguez, la que quizá sea la documentalista más importante del cine en Colombia. Tras cursar el bachillerato en Bogotá, estudia Filosofía y Letras en la Universidad de 
Columbia, en Estados Unidos (Torres San Martín, 2015, p. 160). Todo su trabajo está motivado por la difusión de las manifestaciones culturales colombianas en riesgo de desaparición. Los santísimos hermanos (1969), su última película, establece un paralelismo entre la imagen y la banda sonora en el que, como ocurre en Hermógenes Cayo (Imaginero) (1969) de Jorge Prelorán, marca un nivel de referencialidad independiente y complementario que impulsa la renovación del documental etnográfico en la década de los sesenta e influye en películas posteriores como Chircales (1972) de Marta Rodríguez y Jorge Silva. Tras sufrir la represión del régimen de Pastrana, que la torturó y encarceló acusada de pertenencia al Ejército de Liberación Nacional (ELN) colombiano a comienzos de los setenta, se trunca su vida y la carrera cinematográfica de una mujer diferente, cuya obra supuso una gran contribución al aumento de la presencia femenina en la esfera intelectual y cinematográfica colombiana.

Las películas de la también colombiana Marta Rodríguez suponen un aporte fundamental en el contexto del Nuevo Cine Latinoamericano, que utiliza el documental como herramienta para el cambio social en cintas como Chircales (1972), Planas, testimonio de un etnocidio (1971), Campesinos (1976), La voz de los sobrevivientes

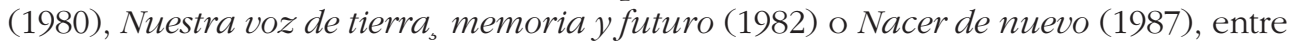
otras. Su mirada etnográfica se construye en Francia bajo la tutela de Jean Rouch y en Bogotá, donde estudia Antropología en la Universidad Nacional. Pero esta mirada evoluciona hacia una vertiente social que marcará toda su filmografía. Lo hace junto al operador y fotógrafo Jorge Silva, con el que forma equipo hasta la muerte de éste en 1987, momento en el que Rodríguez continúa dirigiendo cine en solitario con títulos como Amor, mujeres y flores (1988), Memoria viva (1993), Amapola: la flor maldita (1998), Los bijos del trueno (1999), Nunca más (2001) o Testigos de un etnocidio: memorias de resistencia (2011), poniendo el foco en colectivos marginados y en las injusticias que sufren.

La chilena Angelina Vázquez se integra ya en una generación de cineastas que desarrollan su trayectoria influida intensamente por las pautas que marca la llegada del Nuevo Cine Latinoamericano. Colabora con Patricio Guzmán en La respuesta de octubre (1972), para pasar a formar parte del Equipo Tercer Año con el que realiza La batalla de Chile (1975-1979) y tras el golpe de estado de 1973 parte al exilio. Se instala en Finlandia, donde dirige Presencia lejana (1982), en la que establece un diálogo entre el cine ensayo y el Cine Directo que plantea ya los nuevos caminos por los que el cine documental va a transcurrir en la década de los ochenta. Su estancia obligada fuera de Chile, tanto en Finlandia como en España a partir de 1984, no la alejan de la no ficción; en esta época dirige Apuntes nicaragüenses (1982), Fragmentos de un diario inacabado (1983), Notas para un retrato de familia (1989) y Empresarias de Madrid (1989), todas películas que tienen la distancia, la pérdida y el exilio como temas transversales.

Mari Carmen de Lara es una de las principales figuras de la cinematografía documental mexicana. Su extensa e intensa filmografía, de fuerte orientación feminista, no la ha alejado del trabajo institucional. Vinculada desde el inicio de su carrera al Centro Universitario de Estudios Cinematográficos de la Universidad Autónoma de México, en 2015 es nombrada directora de este. Ha dirigido más de veinte películas hasta la fecha, producidas en muchos casos por Calacas y Palomas, una empresa fundada por ella misma en 1983. Con No les pedimos un viaje a la luna (1986), realiza un retrato de la realidad laboral de las costureras de Ciudad de México que viven situaciones de semi esclavitud y que ven cómo en el terremoto que asola la ciudad en 1985 pierden 
sus viviendas y centros de trabajo. Cabe destacar que el equipo técnico que forma parte de la película está compuesto en su totalidad por mujeres en un ejercicio de la directora por empoderarlas en un sector mayoritariamente dominado por la presencia masculina (Torres San Martín, 2003, p. 392).

A partir del año 1990 la presencia de las realizadoras en la muestra se intensifica exponencialmente. Como se ha comentado, esta tendencia se ha visto apoyada por factores como la llegada del vídeo y los formatos digitales que abaratan los costes y permiten el desarrollo de proyectos independientes con mayor libertad y la proliferación de escuelas y centros de formación sobre cine y medios audiovisuales, además de por factores estructurales como el aumento de la clase media en distintos países en la región.

Ana Poliak es una de las principales renovadoras del género documental en Argentina en los últimos años del s. XX con iQué vivan los crotos! (1990). Imprime en toda la obra una composición casi pictórica en la elaboración de las tomas y una variedad de encuadres propia del cine argumental, con presencia de primeros planos y planos generales con alto valor simbólico, de la misma forma que hiciera Margot Benacerraf en Araya (1959), pero evolucionando la combinación de géneros mediante una simbiosis narrativa entre la representación de los recuerdos del protagonista de la historia y su presencia ante la cámara.

El cine de orientación indigenista y social, del que son grandes exponentes Gabriela Samper con Los santísimos hermanos (1969) o Marta Rodríguez con películas como Planas, testimonio de un etnocidio (1971), Campesinos (1976) o La voz de los sobrevivientes (1980), tiene también su representante en la década los noventa dentro del equipo formado por Vincent Carelli y Dominique Gallois y el trabajo realizado durante varios años en la investigación académica y en las producciones audiovisuales en distintas comunidades indígenas de Brasil. El de la documentalista francesa es un ejemplo de realizadora que se instala en la región sin ser de origen latinoamericano, en este caso en Brasil, vinculada a la Universidad de São Paulo y al proyecto Video nas Aldeias. Junto a Vincent Carelli dirige A arca dos Zo'é (1993), una original película en la que se redefine el formato narrativo documental en el cine etnográfico mediante la asunción del protagonismo por parte de los miembros de las propias comunidades, portando incluso una de las dos unidades de grabación que participan en el rodaje de la película (Calvo de Castro, 2018b, p. 17). Dominique Gallois dedica su vida a la investigación y a la defensa de los derechos de los pueblos indígenas de Brasil y considera el cine documental como una herramienta para generar conciencia social, pero también como mecanismo de expresión de las propias comunidades.

\subsection{Los equipos mixtos de realización en el documental en América Latina}

A medida que el género documental va madurando se intensifica también la presencia de binomios de dirección en los que las realizadoras de cine documental son habituales. Si la carrera en común de Jorge Silva y Marta Rodríguez se vio interrumpida con la muerte del primero en 1987, continuando Rodríguez una prolífica trayectoria en solitario, en décadas posteriores han surgido equipos de trabajo que han dado lugar a películas de cabecera para esta etapa del cine documental en América Latina, como Por esos ojos (1997) de Gonzalo Arijón y Virginia Martínez, Tinta roja (1997) 
de Carmen Guarini y Marcelo Céspedes, Un hombre aparte (2001) de Bettina Perut e Iván Osnovikoff o Yo no sé qué me han hecho tus ojos (2003) de Lorena Muñoz y Sergio Wolf. La explicación del nutrido número de grupos de realización en el cine documental latinoamericano puede estar en la misma esencia de los proyectos documentales, donde las distintas funciones son asumidas por el reducido equipo humano que participa en el proceso de producción. La presencia de dos realizadores permite la división de funciones en contextos que, en muchas ocasiones, suelen requerir de cercanía, discreción y el establecimiento de una relación de confianza con los sujetos protagonistas de las historias documentadas.

Virginia Martínez llega a la dirección de cine documental a través de su vinculación con la televisión uruguaya y la producción cinematográfica del país. La trayectoria de Carmen Guarini es radicalmente diferente ya que, desde que a mediados de la década de los ochenta iniciara su andadura como directora con Buenos Aires, crónicas villeras (1986), ha desarrollado una extensa carrera cinematográfica en el campo del cine documental, compaginada con la docencia y la investigación en distintas instituciones universitarias (Guarini, 2002, p. 113). En el campo de la producción cinematográfica es una de las principales figuras renovadoras del género documental mediante el uso del vídeo como soporte de registro y la introducción de nuevos temas, tras el intenso periodo de militancia política de los y las documentalistas argentinos en el momento de auge del Nuevo Cine Latinoamericano allá por la década de los setenta. En 1986 funda la productora Cine Ojo junto a Marcelo Céspedes que, además de servir de estructura para producir sus propias películas, es la cantera para una nueva generación de documentalistas argentinos, entre los que se encuentran nombres tan relevantes como Alejandro Fernández, Sergio Wolf o Lorena Muñoz. Muñoz, tras cursar sus estudios en Buenos Aires y Cuba, comienza su carrera como cineasta con El rapto de Lena (1997) y Pintor Gómez (1998), dos cortometrajes que cuentan con la producción de su compañía Cine Ojo. En 2001, funda la productora Habitación 15/20 junto a algunos compañeros de profesión y es considerada por parte de la crítica como la sucesora de María Luisa Bemberg, cineasta argentina de los años ochenta y principios de los noventa, que destaca por incluir en sus películas argumentales la defensa de los derechos de la mujer. Lorena Muñoz formó equipo con el cineasta Sergio Wolf solo en la realización de Yo no sé qué me han hecho tus ojos (2003) para después pasar a la dirección de cine de ficción con títulos como Los próximos pasados (2006) o Gilda, no me arrepiento de este amor (2016), Potro, lo mejor del amor (2018) y a la producción de proyectos cinematográficos de terceros.

Finalizando el repaso por los equipos de realización con presencia femenina, el impulso renovador del cine documental latinoamericano tiene como protagonistas en Chile a la pareja formada por Bettina Perut e Iván Osnovikoff. Ambos han desarrollado en conjunto toda su trayectoria como documentalistas y pertenecen a esa nueva generación de cineastas responsables de la reconfiguración del género mediante la incorporación de la transgresión y la vanguardia creativa en un cine documental algo adormilado en décadas anteriores con títulos como El astuto mono Pinochet contra la moneda de los cerdos (2004), Welcome to New York (2006), Noticias (2009), La muerte de Pinochet (2011), Surire (2015) o Los Reyes (2018). 


\subsection{La consolidación}

Otro caso singular es el de la francesa Florence Jaugey que ha vivido desde los años ochenta entre Nicaragua y México. Actriz y directora formada en Francia, en 1984 acude a un rodaje en Nicaragua, cuando su carrera ya estaba consolidada como intérprete en el teatro y la televisión. El impacto de aquella realidad fue tal que cuatro años más tarde decide cambiar de vida para instalarse en Nicaragua. Se vincula, además, como docente con el Centro de Capacitación Cinematográfica de la Universidad Autónoma de México. Dirige el documental La isla de los niños perdidos (2001), uno de los escasos títulos de relevancia de la cinematografía nicaragüense, totalmente yerma de recursos para poder consolidar una producción estable. Su inmersión en el cine de ficción la llevó a ser nominada a los Óscar en la categoría de mejor película extranjera con La Yuma (2010). Tras ese proyecto dirige el cortometraje documental El engaño (2012), los largometrajes documentales para televisión Sunflowers of Nicaragua (2017) y A speck of blue (2018), además del argumental La pantalla desnuda (2014).

Helena Solberg pertenece a una generación de realizadoras brasileñas que han tenido gran impacto en el cine documental en América Latina. Le siguen nombres como Liliana Sulzbach, María Augusta Ramos o Marília Rocha. Solberg, que reside desde hace más de tres décadas en Estados Unidos, vuelve la mirada hacia su país en películas como Carmen Miranda. Bananas is my business (1995), A conexao brasileira (1982) o Made in Brazil (1987), entre otras. Liliana Sulzbach, con fuertes vínculos con Alemania, país donde se forma y trabaja coyunturalmente, desarrolla su trayectoria profesional vinculada a la producción y dirección en el ámbito de la televisión pública, además de dirigir el largometraje documental La cárcel y la calle (2004) y los cortometrajes documentales $A$ Invenção da Infância (2000) y A Cidade (2012). La justicia y el sistema penitenciario en diversos lugares en América Latina son temas recurrentes en el género documental. Lecumberri, El Palacio Negro (1976), de Arturo Ripstein, La isla de los niños perdidos (2001), de Florence Jaugey, Claudia (2010), de Marcel Gonnet Wainmayer y La cárcel y la calle (2004), de la propia Sulzbach, son algunos ejemplos, completados con Justicia (2004), de María Augusta Ramos. Alumna de Johan van der Keuken en Holanda, Ramos plantea una película en la que se realiza un análisis del sistema judicial de Brasil a partir de la relación que se establece entre juez y acusado. Justicia (2004) supera el tono de denuncia al que tanto acudieron las películas pertenecientes al Nuevo Cine Latinoamericano en la década de los setenta, para abordar, con un estilo directo a la manera del fly on the wall del Direct Cinema de Frederick Wiseman en Estados Unidos, un registro observacional con la cámara fija, en la que la realidad fluye libre para construir una historia que el espectador debe dotar de sentido.

En Argentina tiene lugar un proceso similar al de Brasil. Las directoras argentinas de la última época, si bien tienen como precursora a Carmen Guarini, se han situado en lo más alto del cine documental del país con títulos clave para la consolidación del género. Mariana Arruti, Albertina Carri y María Inés Roqué -argentina, aunque radicada en México- son algunos casos analizados a continuación.

Mariana Arruti se forma como antropóloga y directora de cine antes de pasar a formar parte de la Fundación Alumbrar y especializarse en su faceta académica en el cine documental vinculado a los derechos humanos y la recuperación de la memoria histórica. Con Trelew (2003) continúa el trabajo de toda una generación de cineastas de la memoria, que no vivieron la dictadura argentina o eran muy jóvenes cuando se 
produjo y que en la actualidad recuperan los hechos desde la distancia que otorga el tiempo y la pérdida de familiares, como es el caso de María Inés Roqué con Papá Iván (2000) y de Albertina Carri con Los Rubios (2003). La primera, afincada en México desde su niñez, desarrolla su trayectoria como cineasta desde el país norteamericano. Hija de Juan Julio Roqué y Azucena Rodríguez, tras la muerte del primero, en 1977, todavía siendo una niña, se traslada a México con su hermano y su abuela. Papá Iván (2000) es un intento de reconstruir la vida de su padre generando su identidad. Se referencia, así, su papel en la historia, en la película y en el proceso de búsqueda.

La manera de contar su propio proceso en Los Rubios (2003) sitúa a Albertina Carri como una de las cineastas de referencia de su generación en la producción independiente argentina. Hija de Roberto Carri y Ana María Caruso, militantes del grupo Montoneros, y desaparecidos en 1977, tras finalizar su formación cinematográfica se dedica a filmar historias vinculadas con la memoria del periodo de la dictadura en Argentina, pero sobre todo a impulsar proyectos vinculados a los derechos de la mujer con su productora Torta, creada en 2010. Se introduce además en el ámbito de las videoinstalaciones y los contenidos televisivos realizando la serie 23 pares (2012), La bella tarea (2013). La búsqueda de los límites del documental y la experimentación en nuevos territorios creativos renace en el documental Cuatreros (2016), en el que se referencia el proceso de búsqueda como ocurre en Los Rubios (2003). La confrontación intrínseca al proceso de búsqueda también queda patente en su última producción hasta la fecha Las hijas del fuego (2018), en este caso en la búsqueda de los límites del erotismo de los empleados.

En México, junto a la argentina María Inés Roqué, destaca, en el último periodo, Alejandra Islas con Muxes: Auténticas, intrépidas y buscadoras de peligro (2005), documental que aborda otro de los temas fundamentales de la renovación del cine documental en América Latina, las cuestiones vinculadas a la identidad sexual con perspectiva LGTBI+. Películas como Yo la más tremendo (1995), de Aldo Garay, Hotel Gondolin (2005), de Fernando López Escrivá o Este pueblo necesita un muerto (2005), de Ana María Monroy, ayudaron a abrir el camino en el tratamiento de un tema controvertido todavía en muchos lugares y que en la película de Islas se presenta desde un enfoque positivo. La mezcla de los tabús, derivados de la homosexualidad y la represión del periodo de la dictadura en Paraguay dan lugar a Cuchillo de palo (2010), de Renate Costa. La realizadora, tras desarrollar su carrera en diversas producciones televisivas y formarse en Paraguay y Cuba, acude en 2009 a Barcelona a cursar el Máster en Documental de Creación de la Universidad Pompeu Fabra en 2009 (Acevedo, 2011). El trabajo de fin de curso se transformó en este tremendo documental estratificado en varias capas de análisis, como son la represión de los homosexuales y los prejuicios de la sociedad paraguaya, la recuperación de la figura de su tío muerto, la búsqueda de explicaciones y de información sobre lo que le pudo pasar y la relación de Renate Costa con su padre. Estas cuestiones autorreferenciales analizadas en un contexto más amplio son también introducidas por El diablo nunca duerme (1994), de Lourdes Portillo, e Intimidades de Shakespeare y Victor Hugo (2008), de Yulene Olaizola. Dos películas de investigación que se constituyen en investigaciones en sí mismas, en las que, a partir de la indagación de cuestiones personales o familiares, trascienden hacia la delimitación de una serie de cuestiones fundamentales sobre una problemática social.

En Cuba, tras la fallecida Sara Gómez, Susana Barriga representa la renovación del cine documental en la isla. Formada en Escuela Internacional de Cine y Televisión 
de San Antonio de los Baños (EICTV), y habiendo cursado estudios de Psicoanálisis, Historia del Arte y Filosofía en España, la directora vuelca en su cine una manera de ver el mundo y representarlo condicionada por estas líneas académicas, proponiendo el ensayo audiovisual como género documental en sus tres películas hasta la fecha, Patria (2008), Cómo construir un barco (2008) y The Illusion (2009), con la que rompe los límites de la autorreferencialidad en la búsqueda de su padre, quien abandonó a la familia y al que encuentra en Londres en el transcurso de la película.

Por último, aparecen dos realizadoras venezolanas, Patricia Ortega y Yanilú Ojeda, las dos de la región de la Guajira y las dos orientadas hacia un cine -argumental y documental- que defienda los derechos de la comunidad wayúu, con la que tienen una especial vinculación y con la que trabajan también en labores docentes para la capacitación de las nuevas generaciones en la región en el uso de herramientas audiovisuales como mecanismo de expresión y reivindicación de sus derechos. Es la wayúu una población relegada al ostracismo por los gobiernos de Colombia y Venezuela y desplazada en numerosas ocasiones de sus territorios ancestrales por intereses comerciales, mineros y petroleros.

\section{CONClusiones}

Tras este breve recorrido por la aportación y el rol desempeñado por las mujeres realizadoras en el cine documental de América Latina, se puede concluir que en las décadas de los cuarenta y cincuenta, aparecen figuras relevantes -por su trascendencia y por su excepcionalidad-como Carmen Toscano y Margot Benacerraf. Estas cineastas, teniendo en cuenta el contexto de producción cinematográfica de los distintos países de la región, aportan películas que son el germen del Nuevo Cine Latinoamericano. Son pioneras en el cine documental de la región, pero también contribuyen, con sus películas, cuestiones esenciales para la evolución del género documental.

De igual manera, tras el agotamiento de los modelos propuestos por el Nuevo Cine Latinoamericano y ya en las décadas de los setenta y ochenta, aparecen cineastas como Marta Rodríguez, Angelina Vázquez o Mari Carmen de Lara, que se insertan en la redefinición de los postulados del cine documental junto a Carmen Guarini, Ana Poliak o Helena Solberg. Por tanto, sus aportaciones al género en la región son cruciales para la evolución de este, pero también suponen una referencia para las generaciones futuras.

Estas generaciones, a finales de los noventa y sobre todo ya en el s. XXI, se han visto favorecidas por los avances sociales, culturales y educativos producidos en la región y han contribuido a favorecer la presencia e influencia de la mujer en el contexto de producción del cine documental. A medida que acceden al mercado de trabajo y a las instituciones educativas superiores, la presencia, también en este ámbito concreto, se ve fortalecida y el número de mujeres realizadoras aumenta exponencialmente.

Desde un punto de vista puramente cinematográfico y analizando los títulos seleccionados en la muestra dirigidos por mujeres, se puede concluir tras lo descrito en el presente artículo que su presencia impulsa un cine documental con mayor grado de experimentalidad, más maduro y consolidado como herramienta de defensa de los derechos sociales y ciudadanos y de preservación de la memoria histórica en América Latina, lo que supone un aporte fundamental para el género en la región. 
Este estudio transversal es un punto de partida que futuras investigaciones deberán afrontar a partir de las aportaciones de las realizadoras de documentales en las principales cinematografías nacionales del contexto latinoamericano a lo largo de los distintos periodos del cine documental. Además, las reflexiones de las cineastas, muchas de ellas activamente comprometidas con los postulados teóricos y críticos de la evolución del formato en el que expresan su mensaje, tienen un gran interés en contextos académicos, pero también en los que conectan este mensaje con la sociedad como festivales, encuentros o talleres. Son estas documentalistas, las que en el momento de abordar una realidad social para plasmarla en una película documental se convierten en observadaorass privilegiadas de los problemas y retos que debemos afrontar en tanto vivimos en sociedad.

\section{Bibliografía}

Acevedo, A. (2011). Entrevista a Renate Costa. [contenido del blog El pijama de Hepburn]. Recuperado el 20 de septiembre de 2017. Disponible en https://goo.gl/A9qSRr [Consulta: 26-09-2018]

Austin, T. y De Jong, W. (2008). Rethinking Documentary. New Perspectives, New Practices. Maidenhear: OUP/McGraw-Hill.

Aumont, J. y Marie, M. (1990). Análisis del film. Barcelona. Paidós.

Barnouw, E. (1996). El documental, historia y estilo. Barcelona: Gedisa.

Bernárdez-Rodal, A. y Padilla-Castillo, G. (2018). Mujeres cineastas y mujeres representadas en el cine comercial español (2001-2016). Revista Latina de Comunicación Social, 73, 12471266. DOI: $10.4185 /$ RLCS-2018-1305

Bordwell, D., Staiger, J. y Thompson, K. (1997). El cine clásico de Hollywood. Estilo cinematográfico y modo de producción hasta 1960. Barcelona: Paidós.

Burton, J. (1990). The Social Documentary in Latin América. Pittsburg: PAU. Of Pittsburg.

Caballero, R. (2006). Producción, coproducción e intercambio de cine entre España, América Latina y el Caribe. Avances de investigación 5. Madrid: Fundación Carolina CeALCI.

Calvo de Castro, P. (2018a). El acceso a la formación especializada de las documentalistas en América Latina. Análisis de su evolución como explicación de un cambio de paradigma. Comunicación y Género, 1(2), 161-171. doi:10.5209/CGEN.62673 [Consulta: 15-03-2019]

Calvo de Castro, P. (2018b). La evolución del cine documental de corte etnográfico en América Latina, Revista cine documental, 17, 1-23 https://goo.gl/Tcc3s3 [Consulta: 15-3-2019]

Cerdán Los Arcos, J. (2015). Un lugar ético para las imágenes documentales (en el contexto de las ciencias sociales), en Fernández Guerra, V. (Coord.). Revisitando el documental; de Flaherty al webdoc. Cuadernos Artesanos de Comunicación. N. 83. La Laguna (Tenerife): Latina. Disponible en https://goo.gl/QWM3BR [Consulta: 26-09-2018]

Chanan, M. (2007). El documental en el espacio público. Archivos de la filmoteca: Revista de estudios históricos sobre la imagen, 57, 68-89. Disponible en https://goo.gl/CJcRXo, [Consulta: 15-03-2019].

Diéguez, D. C. (2012). ¿Ellas miran diferente? Temas y representaciones de las realizadoras en Cuba. Varia, 20, 150-162. Disponible en https://goo.gl/7kTGKp [Consulta: 26-09-2018]

Everly, K. (2016). Acercamientos feministas al cine español y latinoamericano: la mujer como producto y productora de imágenes. Languages, Literatures, and Linguistics, 19, 179-193. DOI: https://doi.org/10.1353/hsf.2016.0037 [Consulta: 26-09-2018]

Felitti, K. y Rizzotti, A. (2016). El "machismo latinoamericano" y sus derivas en la educación internacional: reflexiones de estudiantes estadounidenses en Buenos Aires. magis, Revista Internacional de Investigación en Educación, 9(18), 13-28. Doi: 10.11144/Javeriana.m9-18. mlde [Consulta: 4-12-2018]

Flick, U. (2002). An introduction to Qualitative Methodology. Chicago: Markham. 
Gómez Tarín, F. J. (2006). El Análisis de un texto fílmico. Castellón: Beira Interior.

Gómez Tarín, F. J. (2011). Elementos de Narrativa Audiovisual. Expresión y narración. Santander: Shangrila.

Gómez Tarín, F. J. \& Marzal Felici, J. (2006). Una propuesta metodológica para el análisis de un texto fílmico. Actas del III congreso internacional de análisis textual: De la deconstrucción a la reconstrucción. Asociación Cultural Trama y Fondo (pp. 1-18) [https://goo.gl/zXxkFh].

Guarini, C. (2002). Memoria Social e imagen. Cuadernos de antropología social, 15, 113-123. Disponible en https://goo.gl/PVPasM [Consulta: 15-03-2019]

Gumucio Dagron, A. (1982). Historia del cine en Bolivia. La Paz: Los amigos del libro.

Gumucio Dagron, A. (2003). Jorge Ruiz. En Paranaguá, P. A. (Ed.), Cine documental en América Latina (pp. 141-149). Madrid: Cátedra.

Gumucio Dagron, A. (2011). Comunicación para el cambio social: clave del desarrollo participativo. Signo y Pensamiento, 30 (58), 26-39. Disponible en https://goo.gl/a1GKeE [Consulta: 15-03-2019]

Gumucio Dagron, A. (2014). El cine comunitario en América Latina y el Caribe. Bogotá: Fundación Friedrich Ebert. Disponible en https://goo.gl/9sf7je [Consulta: 15-3-2019]

Gutiérrez San Miguel, B. (2015). Estudio evolutivo del lenguaje narrativo, desde los primeros documentales a los transmedia. En V. Fernández Guerra (Ed.), Revisitando el documental; de Flaberty al webdoc. Cuadernos Artesanos de Comunicación. 83. La Laguna (Tenerife): Latina. Disponible en https://goo.gl/KiEXWz [Consulta: 26-09-2018]

Iglesias, N. y Fregoso, R. L. (1998). Miradas de mujer: Encuentro de cineastas y videoastas mexicanas y chicanas. Tijuana: Colegio de la Frontera Norte.

King, J. (1994). El carrete Mágico. Una historia del cine latinoamericano. Bogotá: Tercer Mundo.

Lie, N. y Piedras, P. (2014). Identidad y movilidad en el cine documental latinoamericano contemporáneo: Familia Tipo (2009) e Hija (2011). Confluencias: Revista Hispánica de Cultura y Literatura, 30 (1), pp. 72-86. doi:10.1353/cnf.2014.0009

Mamblona, R. (2012). Las nuevas subjetividades en el cine documental contemporáneo. Tesis doctoral. Universitat Internacional de Catalunya, Barcelona, España. Recuperado el 20 de marzo de 2019, disponible en

Martínez-Salanova Sánchez, E. (2003). El valor del cine para aprender y enseñar. Comunicar, 20, 45-52. Disponible en https://goo.gl/majEmM [Consulta: 26-09-2018]

Miquel, D. y Wood, D. (2016). El cine de compilación de la Revolución Mexicana. Vivomatografías. Revista de estudios sobre precine y cine silente en Latinoamérica. 2 (2), 6-12. Disponible en https://goo.gl/gRi65D [Consulta: 13-10-2018]

Montiel, A. (2002). El desfile y la quietud. Análisis fílmico versus Historia del Cine. Valencia: Generalitat Valenciana.

Mraz, J. (1990). Santiago Álvarez: From the dramatic form to Direct Cinema. En Burton, J. (Ed.), The Social Documentary in Latin América (pp. 131-149). Pittsburg: PA U. Of Pittsburg.

Mulvey, L. (1975). Visual Pleasures and Narrative Film. Screen 16.3: 6-18.

Nichols, B. (1991). La representación de la realidad. Cuestiones y conceptos sobre el documental. Barcelona: Paidós.

Nichols, B. (2013). Introducción al documental. México DF: UNAM.

Paranaguá, P. A. (1984). O Cinema na América Latina. Porto Alegre: L\&PM Editores.

Paranaguá, P. A. (2003a). Cine documental en América Latina. Madrid: Cátedra.

Paranaguá, P. A. (2003b). Tradición y modernidad en el cine documental en América Latina. Bogotá: Fondo de Cultura Económica.

Paranaguá, P. A. (2009). El nuevo documental brasileño, una breve reseña. Cinémas du réel en Amérique latine, 92, 57-69.

Ortega, M. L. (2007). De memorias y olvidos. El documental latinoamericano contemporáneo. Cuadernos hispanoamericanos, 679, 19-27.

Ortega, M. L. (2008). Cine directo, reflexiones en torno a un concepto. Madrid: T\&B Editores.

Ortega, M. L. (2009). De la certeza a la incertidumbre: collage documental y discurso político en América Latina. En García López, S. y Gómez Vaquero, L. (Eds.), Piedra papel y tijera: el 
collage en el cine documental (pp. 101-138). Madrid: Ocho y Medio. Disponible en https:// goo.gl/WqanWY [Consulta: 15-03-2019].

Ortega, M. L. (2010). Nuevos tropos en el documental latinoamericano: subjetividad, memoria y representación. En Weinrichter (Ed.), El documentalismo en el s. XXI (pp. 77-99). San Sebastián: Festival de cine de San Sebastián. Disponible en https://goo.gl/QggDwL [Consulta 15-03-2019].

Quiroga Echevarría, M. C. (2007). Inicios del documental con fines didácticos en México. Ciencia UAT, 1 (3), 40-43. Disponible en https://goo.gl/YLohra [Consulta: 17-10-2018].

Renov, M. (1993). Theorizing Documentary. New York: Routledge.

Renov, M. (2004). The Subject of Documentary. Mineapolis: University of Minnesota Press.

Romero Chumacero, L. (2005). Rastreando la tarea de los tejidos y los sueños: la recepción de rueca. Tema y variaciones, 25, 105-119. Disponible en https://goo.gl/5bWmmn [Consulta: 13-12-2018]

Ruffinelli, J. (2001). Patricio Guzmán. Madrid: Cátedra.

Ruffinelli, J. (2010a). América Latina en 130 películas. Santiago de Chile: Uqbar Editores.

Ruffinelli, J. (2010b). Yo es/soy el otro. Variantes del documental subjetivo o personal. Acta sociológica, 53, 59-81. Disponible en https://goo.gl/zYkHft [Consulta: 15-03-2019].

Ruffinelli, J. (2012). América Latina en 130 documentales. Santiago de Chile: Uqbar Editores.

Ruso, E. (1998). Diccionario de Cine. Barcelona Paidós.

Tay, S. L. (2009). Women on the Edge: Twelve Political Film Practices. Nueva York: Palgrave Macmillan.

Tirado, R. (1988). Memorias y notas del cine venezolano 1897-1959. Caracas: Ateneo de Caracas.

Torres San Martín, P. (2003). No les pedimos un viaje a la luna (Mari Carmen de Lara, México, 1986). En Paranaguá, P. A. (Ed.), Cine documental en América Latina (pp. 391-393). Madrid: Cátedra.

Torres San Martín, P. (2013). Elena Sánchez Valenzuela. En Gaines, J. Vatsal, R. y Dall'Asta, M. (Eds.) Women Film Pioneers Project. Nueva York: Columbia University Libraries Web. Disponible en https://goo.gl/JFqXsD [Consulta: 26-09 2018]

Torres San Martín, P. (2014). Cineastas de América Latina, desacatos de una práctica fílmica. Femmes de cinema, 22, 24-37. Disponible en https://goo.gl/JupjZb [Consulta: 26-09-2018]

Torres San Martín, P. (2015). Cine latinoamericano de mujeres: memoria e identidad. Revista de Estudios de Género, La Ventana, 4, 151-171. Disponible en https://goo.gl/cEFnrY [Consulta: 26-09-2018] 
